\title{
“Seek any means, and keep it your secret": Young women's attempts to control their reproduction through contraceptive and fertility practices in rural Tanzania
}

\author{
M.L. PLUMMER ${ }^{1 *}$, J. WAMOYI ${ }^{2}$, Z.S. SHIGONGO ${ }^{2}$, G. MSHANA ${ }^{3}$, A.I.N. OBASI ${ }^{4}$, D.A. ROSS ${ }^{1}$ and \\ D. WIGHT ${ }^{5}$ \\ ${ }^{1}$ Department of Epidemiology and Population Health, London School of Hygiene and Tropical Medicine, \\ Keppel St., London, WC1E 7HT, UK \\ ${ }^{2}$ NIMR/AMREF/LSTM/LSHTM Collaborative Projects, P.O Box 1462, Mwanza, Tanzania \\ ${ }^{3}$ National Institute for Medical Research, PO Box 1462, Mwanza, Tanzania \\ ${ }^{4}$ Liverpool School of Tropical Medicine, Pembroke Place, Liverpool L3 5QA, UK \\ ${ }^{5}$ Social and Public Health Sciences Unit, Medical Research Council, 4 Lilybank Gardens, Glasgow G12 8RZ, \\ UK
}

\begin{abstract}
This study examined young women's attempts to control reproduction through contraception and fertility protection or promotion in rural Tanzania. It drew on participant observation in nine villages, group discussions and interviews in three others, and 16 health facility simulated patient visits from 1999-2002. Fertility was highly valued, but out-of-wedlock pregnancies were stigmatized. Many girls used traditional contraception, such as wearing charms or drinking ash solutions. Young single mothers sometimes used modern contraception, including Depo Provera, because injections were accessible, private, and infrequent. However, use was ambivalent and inconsistent for fear of side effects, such as infertility (hormonal contraceptives) and reduced male pleasure (condoms). Newly married women tried to conceive immediately. Traditional treatments were used for infertility, miscarriage, or difficult deliveries. These were attributed to physical causes (sexually transmitted infections; contraception; abortion) and/or supernatural causes (God's will; witchcraft; ancestral punishment). Improved reproductive health education and services are greatly needed. The potential of condoms to protect future fertility should be emphasised.
\end{abstract}

Keywords: Young women, fertility, contraception, rural Africa, Tanzania

\section{Introduction}

Historically, fertility has been highly valued in Sub-Saharan Africa as both economically and socially rewarding. Early and universal female marriage, an emphasis on immediate conception, and extremely low rates of effective contraception have contributed to women giving birth to an average of six or seven children in their lifetimes (Caldwell \& Caldwell, 1987; Cohen, 1998). However, fertility has declined in recent decades, particularly in urban areas, primarily due to greater use of modern contraception (Kirk \& Pillet, 1998), and, to a lesser extent, older age at first marriage (Cohen, 1998; Harwood-Lejeune, 2000) and the HIV epidemic (Hinde \& Mturi, 2000; Terceira et al., 2003; Dyer, 2008a).

The meaning and importance of contraception and fertility can vary considerably at different stages in a woman's life. Contraceptive motivation and practices prior to marriage or childbearing (e.g. avoiding pregnancy in a secretive sexual relationship) may vary markedly from those after marriage or first birth (e.g. increasing the time between

\footnotetext{
* Dr. Mary L. Plummer; E-mail: mary.plummer@lshtm.ac.uk
} 
children). A large proportion of young, unmarried rural women may be sexually active for several years prior to independent adulthood and/or marriage, but little research has examined their contraceptive and fertility-related beliefs and practices (Castle, 2003; Williamson et al., 2009). Most research with adolescents has examined modern contraceptive use through surveys of urban youth and/or secondary school students, which is likely to have limited validity and representativeness for the broader population. A recent review of qualitative studies of young women's use of modern contraception in developing countries only identified six studies of high standard in Sub-Saharan Africa, most of which were conducted in urban or semi-urban settings and did not discuss use of traditional methods in detail (Williamson et al., 2009).

Until 1994, contraceptive counselling and services in Tanzania were only officially allowed for child-spacing purposes, after which revision of the National Policy Guidelines and Standards for Family Planning allowed adolescents access to contraceptives, irrespective of parity or marital status (Silberschmidt \& Rasch, 2001). By the 2004-2005 Tanzanian Demographic Health Survey, 12\% of 15-19 years old women reported ever having used a contraceptive method, mainly condoms (7\%), traditional methods $(4 \%)$, oral contraceptives $(3 \%)$, and injectables $(2 \%)$, compared to $45 \%$ of $20-24$ year olds and $59 \%$ of $25-29$ years olds (NBS/ORC-Macro, 2005). Over onethird of the 15-19 years olds who had used a contraceptive only did so after having a child (NBS/ORC-Macro, 2005). Adolescent modern contraceptive users were also disproportionately urban, in part because rural areas commonly face shortages of family planning providers and contraceptives (Chen \& Guilkey, 2003).

Most research has found that infertility in Sub-Saharan Africa is attributed to traditional beliefs about health and illness as well as to biomedical causes, although understanding of the latter is often very limited (Dyer, 2008b). Having biological children - ideally many - is a very important life goal in Sub-Saharan Africa. Women may be anxious to protect or promote their long-term fertility from an early age, even when they do not want to become pregnant in the short-term (Castle, 2003). Considerable effort may also be expended seeking treatment for perceived infertility, but effective treatment can be very difficult to obtain (Dyer, 2008b). In the 2004-2005 Tanzanian Demographic Health Survey, only 2\% of women in their late 40s had never given birth, suggesting a very low rate of primary (permanent) sterility (NBS/ORCMacro, 2005). However, this statistic does not include a much larger proportion of women who had one or more births but were then unable to have more children. A study of 3,708 20-44 year-old Tanzanian women found that 16\% reported having experienced such secondary infertility (Larsen, 2000). In a different study, Mwanza Region had a secondary infertility rate of $18 \%$, which was significantly higher than 18 of the 21 Tanzanian regions studied (Larsen, 2003).

This paper uses data from participant observation, group discussions, in-depth interviews, and simulated patient visits to rural health facilities to examine contraceptive and fertility beliefs and practices among young women in a predominantly Sukuma population in rural north-western Tanzania. It examines how girls and young women attempt to control their fertility through both traditional and modern practices. The data come from a large qualitative study that complemented a 1998-2002 community randomized trial of an adolescent sexual and reproductive health programme, MEMA kwa Vijana (MkV) (Hayes et al., 2005; Ross et al., 2007). This multi-component intervention 
included both an in-school curriculum and a training course for health workers in the provision of youth-friendly services (Obasi et al., 2006). Qualitative findings on other reproductive and sexual health topics have previously been published, including those addressing condom use (Plummer et al., 2006), the consequences of school girl pregnancies (Wight et al., 2006; Plummer et al., 2007), and induced abortion (Plummer et al., 2008).

\section{Materials and Methods}

\section{Study areas}

Participant observation (PO) was conducted in nine villages in Geita, Kwimba, Missungwi and Sengerema Districts of Mwanza Region, Tanzania from 1999-2002 for a total of 158 person-weeks. Villages were selected to represent common farming, fishing, and petty trade settings, and they included both multi-ethnic and almost entirely Sukuma communities.

\section{Data collection}

Six field researchers collected data, with each living in a different household and returning to the same household for repeated visits. Researchers accompanied young people during their routine activities and special events, and wrote field notes for 1-3 hours daily. A detailed description of PO has been published elsewhere (Plummer et al., 2007).

In addition, in August-September 2000, four of the field researchers held a series of semi-structured group discussions (GDs) and follow-up individual interviews (GDIIs) with a male and a female group in each of three representative villages unrelated to the PO villages. Researchers first spent a few days developing rapport with young villagers in public areas, such as markets and sport fields. In each village, they then facilitated 3-4 two-hour discussions with both a male and a female group. Each group consisted of 9-12 young people aged 15-27 years, with mean group ages of 18-21 years. In two villages, the female groups were mainly single young women engaged in petty trading or farming, while in the third village they were mainly primary schools girls or recent school leavers. Most of the male GD participants were farmers, fishermen or cattle herders. After each GD, researchers conducted 15-30 minute in-depth interviews with 2-3 of the GDparticipants. In total, 21 GDs and 50 GDIIs were conducted in this series, but this paper only draws on the six GDs and 14 GDIIs focused on reproduction.

In November-December 2000, as part of the process evaluation of the MkV programme, four 15-17 year old villagers were trained to present themselves at health facilities as patients seeking condoms, birth control, or advice about a possible sexually transmitted infection (STI). These simulated patients were selected from 84 young applicants in a village outside of the study area based on criteria such as confidence, recall, creativity, acting skills, and youthful, rural appearance. MkV health facilities had been informed of, and had agreed to, the possibility of simulated patient exercises (SPEs) approximately six months previously. Ten $\mathrm{MkV}$ intervention and ten comparison health facilities were randomly selected for one simulated patient visit. One of these health facilities was in a PO village, and three were in villages where GDs had been held. Clinical consultations were discreetly tape-recorded, and detailed de-briefing interviews 
were conducted with simulated patients immediately afterwards.

\section{Data analysis}

GDs, GDIIs and SPEs were tape-recorded, and along with PO field notes were transcribed and translated into English, and then coded using 32 broad codes in the NUD*IST Programme Version 4. All data coded under the broad code "reproduction" were subcoded under 18 pre-identified themes (e.g. "reasons to prevent pregnancy", "specific methods", and "fertility beliefs"), plus newly emerging themes (e.g. "effect of other sex partners during pregnancy"). All transcripts were then searched using key roots or words, such as "hirizi" (Swahili for a certain kind of protective charm) or "lwikelo" (Sukuma for a particular pregnancy problem). There were no transcripts available for four SPEs, because one health facility was closed, another did not have condoms available for a condom request, and the two remaining recordings were inaudible. Measures of the quality of clinical consultations (e.g. confidentiality, respectfulness, privacy, service) were ranked for the 16 SPEs for which there were transcripts. Hypothesis generation and testing against the relevant data took place throughout the analysis.

In this paper, words in italics are Swahili, words in bold italics are Sukuma. In GD and GDII transcripts, " $F$ " refers to the facilitator, and " $\mathrm{R}$ " to the respondent. In SPE transcripts, "HW" refers to the health worker, and "SP" to the simulated patient. Codes after excerpts first indicate method, year, trial intervention or comparison status, and village number. Then, for PO and SPE, researcher number and sex are indicated, whereas for GDs and GDIIs, group discussion or interview number and sex are indicated. Examples are PO-02-I-4-1m, GD-00-C-10-2f, GDII-00-C-12-4m, and SPE-00-I-21-7f.

\section{Ethical considerations}

This study was approved by the Tanzanian Medical Research Coordinating Committee and the London School of Hygiene and Tropical Medicine Ethics Committee.

\section{Results}

\section{An overview of young women's attempts to control their reproduction}

In rural Mwanza, having children - especially many children - was generally viewed as a source of pride, accomplishment, and future security by both young men and young women. Many men and some women considered pregnancy to be "God's will" or desirable in any circumstances. The following example was provided by a 16 year old girl who had finished Year 7: "She said that it was not wrong to give birth when not married. She said that, even if she gets pregnant now [before she marries], she can be happy because she will give birth to a child who will later assist her parents by working on the farm" [PO-00-C-3-2f].

Some young unmarried women specifically sought pregnancy in the hope that it would lead to formal or informal marriage with the child's father. Even when a young woman wanted to prevent pregnancy, she might not do so because she did not know how to do so, or she believed that traditional or modern contraception reduced a woman's future fertility. There were many accounts, however, of individuals who tried to prevent pregnancy. School girls and single young women were motivated to prevent pregnancy because of the stigma, punishment, and hardship that were sometimes associated with out-of-wedlock pregnancies. Pre-marital pregnancy could also reduce a woman's bride 
price $^{1}$, create financial or legal burdens for her sexual partner, and limit either partner's choice of spouse. Most girls and women thus hoped to have the financial security and social respectability of a long-term, committed relationship before conceiving a child. Boys and men sometimes held the same goal.

However, most 15 year-old boys and girls had had sexual intercourse, and considered it very difficult and even impossible to abstain, particularly after sexual debut. This conflicted with social norms of student abstinence and female sexual respectability, so adolescents had very secretive sexual relationships. School girls sometimes employed traditional ${ }^{2}$ pregnancy prevention methods, such as wearing charms or drinking herbal or ash solutions. It was not unusual for school pupils who were discovered to be sexually active to be beaten by teachers or parents, and pregnant school girls were expelled. In the following example, a five-month pregnant school girl describes her circumstances: "She said that, since her pregnancy became visible, some of her girlfriends don't visit ... [and] the boy who made her pregnant ran away. ... She said that she will not go to school again because of her pregnancy, although she greatly prefers to continue with education. ... When her parents discovered her condition they scolded her very much while telling her that she has lost a lot of their money [on school fees and reduced bride price]... They went to the boy's home, where they were compensated with two head of cattle and Tanzanian Shillings 30,000 (US\$ 36) 3" [PO-00-I-4-4f].

The vast majority of boys and girls completed primary school in their mid to late teens, and did not go on to secondary school, but instead assumed many responsibilities of adulthood and began working full-time. Almost all young, single women in such circumstances were sexually active, but their sexual relationships were usually carefully concealed, particularly if they still lived within their parents' households. Some young, childless, single women actively tried to prevent pregnancy by relying on traditional methods, but conception outside of an established relationship was fairly common. The vast majority of young women who were faced with such circumstances carried their pregnancies to term, and many of them married the sexual partner who was reputedly responsible for the pregnancy. A small minority of pregnant girls and women felt desperate to end their pregnancies, and attempted to induce abortion.

If a young woman had a baby out-of-wedlock, she was commonly referred to by the term msimbe (plural wasimbe), which sometimes had a negative connotation. One male respondent described an msimbe as "a woman who has delivered a baby. ... If she delivers a baby her breasts will definitely fall. ... You think by looking at her, 'This one is married'. But she may say that she isn't, [so you think] 'Aha, so she is an msimbe'. ..." When asked how someone feels when she is called an msimbe, the young man responded, "Those women themselves feel bad to be called an msimbe" [GDII-00-C-12-4m].

Young mothers, whether married or not, generally had much more access to modern contraceptives than childless single women, because they visited health facilities for prenatal check-ups and their children's health care, and health facility staff specifically

\footnotetext{
${ }^{1}$ Bride price payments varied considerably, but six cattle or the cash equivalent was common.

${ }^{2}$ In this paper, the term "traditional" is used to refer to local, non-western beliefs and practices that were reportedly handed down from prior generations. However, it is possible that some of these were more recently introduced.

${ }^{3}$ At the time of the research the exchange rate was approximately Tanzanian Shillings (TShs) 1,000 to British $£ 0.80$ to US\$1.20. The minimum monthly wage (which was more than many labourers received) was TShs 30,000 .
} 
targeted them for contraceptive advice. However, only a minority of single mothers used modern contraception consistently, for reasons that will be discussed in depth below. Young, single mothers who lived with their parents were expected to be discreet about their sexual relationships, even if they had an on-going partner who was effectively an "open secret". For example, in one village, a woman who lived with her parents felt she must sneak out at night to have sex with the father of her child, even though he was publicly acknowledged in that role, and was on polite terms with her parents.

If a young woman began living with a man, she was essentially considered married. Whether formally or informally married, she was usually then expected to become pregnant soon afterwards. Couples rarely sought to prevent pregnancy early in a marriage. After one or more children, a minority of men and women intentionally wanted to prevent pregnancy in order to space or limit the number of their offspring, and promote their family's quality of life. For example, one young man who had a rice-selling business voiced such an opinion during a conversation with a female acquaintance: "[The woman] criticised the man for having only one child, even though he had been married for three years. The man said he was a modern man and thus knows the importance of family planning. He said that life is not cheap like in the past. She said she preferred someone to have many children, because they will assist with farm work" [PO-00-C-3-2f].

If a woman did not conceive a child within a year of marriage, her partner and his family often became concerned about her fertility. This could lead to traditional treatments to enhance her fertility, and sometimes divorce or marriage to an additional wife. Each of these attempts by young women to control their reproductive potential through traditional or modern methods will be described in more detail below, with the exception of induced abortion, which is described in depth elsewhere (Plummer et al., 2008).

\section{Pregnancy prevention}

Some sexually active, unmarried young women did not want to become pregnant, but they did not actively try to prevent it. Reasons for this included not knowing how to prevent pregnancy (particularly young girls), or believing that they could not become pregnant (e.g. due to young age), that pregnancy prevention was alien or harmful, or that pregnancy was a matter of God's will. For example, a researcher heard the following comments while eating dinner with her participant observation host family one night: "They said that [a female relative] uses a condom during love making, so all of the sperm remain in the condom. They disparaged her, saying that she is copying white people's use of condoms and forgetting her culture, which does not prevent conception/birth" [PO-01-C-2-6f].

Most girls and women reported learning pregnancy prevention methods from older same-sex siblings and cousins, but sometimes also from other female friends, mothers, grandmothers, older women familiar with traditional methods, and traditional healers. Many actively tried to prevent pregnancy, but employed local or traditional methods that were unlikely to be effective. Many never informed their partners that they were attempting to prevent pregnancy, as they believed their partners would oppose it, even within clandestine relationships. As one female GD participant reported: "If you don't want to have a child, seek any means, and keep it your secret. ... You do not tell that young man" [GD-00-C-10-2f].

Few boys or men reported actively trying to prevent pregnancy by using a 
condom or by helping their partner to obtain a different modern method. Those men were usually in highly secretive sexual relationships that would result in very negative consequences if they became known, such as a married man who was sexually involved with a school pupil.

\section{Traditional pregnancy prevention methods}

Traditional pregnancy prevention methods usually fell into two categories: charms that were worn, and solutions of leaves, roots or ashes that were ingested. Drinking a solution of ashes to prevent pregnancy was reported by all GD groups and in all PO districts. Many women reported having used this method, particularly as school girls, because it was free, easy to access, and could be prepared and taken without anyone else's knowledge. For example, a 17 year old married woman who had never gone to school had these to say: "She used to drink wood ashes mixed with water before sexual intercourse to prevent getting pregnant. [She said] the ashes are effective because she never got pregnant [while single]. She also showed me some plants, which she said are used by boiling the roots, and then drinking the contents. She said that it is very bitter, but combined with ashes is very effective" [PO-00-C-3-2f].

Opinions varied about the effectiveness of ashes in pregnancy prevention, possible side effects, what ashes could be mixed with (e.g. local herbs or sodium bicarbonate), and whether to take them before and/or after intercourse. A few respondents reported that strong concentrations could cause infertility, and many reported that ashes were also effective in inducing abortions. A few male GD participants reported that if a man drank an ash solution it made his sperm temporarily ineffective, and one reported doing so himself.

Protective charms were also widely used for pregnancy prevention. These were usually prepared by a traditional healer or an older female family member or acquaintance who claimed knowledge of traditional medicine. Some kinds were worn by a woman for a short time before the charm was buried or hidden (e.g. under a roof) until she wanted to conceive, at which time it would be uncovered or removed. Others were worn by the woman until she wished to conceive. One common method, called a "twig" (kijiti, pigi), involved boring a hole in 1-2 pieces of roots or wood, possibly sealing herbal medicine inside of it, and wearing this on a string or beads around a woman's neck, arm or waist. Another form of contraceptive charm (hirizi) could be made of plant materials sewn between two small pieces of animal hide and worn on a string around the waist. The following example was reported in an in-depth interview following a female group discussion: "One woman from here wears [hirizi] on her waist beads. We were bathing together at the well. I asked her ... and she told me she uses it to not become pregnant. ... I also saw one neighbour, she was married there just near our home. After having two children she vowed not to give birth again, so she said, 'Let me look for traditional medicine or any medicine so that I stop [conceiving]. ... I want to have a break'. Then she went to a female traditional healer to have that medicine [pigi] made for her. Yes, that stopped her from getting pregnant. She hasn't conceived up to now" [GDII-00-C-11-5f]. Similarly, following a male group discussion, a male in-depth interview respondent reported: "I have seen a certain person who proves that a [pigi] works. My aunt, who used to stay at our home, she is the one who had it. It's when I came to know that in fact it really works, because she herself stayed for about fifteen years without having a baby, but she was going [having sex] with men" [GDII-00-C-12-4m].

PO researchers often observed adolescent girls and single young women wearing 
protective charms, and their use was so common as to be an "open secret". However, they were often worn discreetly out of sight, and if asked directly, a girl or woman could claim to wear the charm for other reasons than contraception, such as to treat an illness.

Participants from multiple PO and GD villages reported that pregnancy could be prevented by drinking teas made from the roots, stem or other parts of certain plants, such as the leaves of the neem tree (Azadirachta indica). These teas might be drunk alone, or combined with wood ashes. Less commonly reported traditional or local practices believed to have long-term contraceptive effects included placing traditional medicine in an incision made in a woman's skin; mixing and burying certain substances (e.g. herbs and ashes, a woman's menstrual blood, or her child's faeces) in the earth; or swallowing solutions made from certain plant and/or animal materials that a traditional healer placed on a woman's tongue, each drop representing a year of not conceiving. The following example was provided by a nurse in her 30s: "She talked about one woman who uses special slivers of wood, which she dips in her menstrual blood on the first day of her menses. She said that after doing this, you bury them without being seen by anyone. Then, if you later want to conceive, you unearth them. [She said] after seeing them, if you have sex you will definitely get pregnant" [PO-02-C-3-3m].

Occasionally respondents voiced doubt about the safety of traditional pregnancy prevention methods, for example, that if a pigi string broke accidentally, or a woman forgot where she had buried a contraceptive charm, she might become permanently infertile. Most respondents believed that such methods were effective. As one male GD participant commented, "With that [charm], no matter how many times you do it, no matter how long you have sex, there will be no pregnancy" [GD-00-C-12-2m]. However, some questioned their effectiveness, particularly if they knew someone who became pregnant while using them. For example, one respondent said: "They once tied those pigi that they talk about on [my waist] ... I was surprised to become pregnant while wearing it. ... So I told the traditional healer, 'Healer, you completely deceived/tricked me, you!' [The healer replied,] 'You probably dropped [the pigi].' I said, 'No, you deceived me and, now I'm pregnant. ... You have brought problems to me"' [GD-00-C-10-3f].

\section{Modern pregnancy prevention methods}

In both PO and GDs, few young people reported having used modern contraceptives themselves. Reports about them were usually third-person observations and opinions rather than personal experience. Reports of school girls using modern contraception were extremely rare. Judgment about adolescent pregnancy prevention could be harsh, as evidenced by the comment of a 20 year old unmarried woman who sold produce: "Birth control pills are only used by adults, particularly those who are married. When a girl uses contraceptive pills, she must be a prostitute" [PO-02-I-4-5f]. Even if school girls were aware that such options were available at health facilities, they were very unlikely to seek them out, because of distance to facilities and, most importantly, fear that health workers would judge them and discuss their visit with other villagers. Such concerns were not unfounded; for example, most villagers needed to walk 3-10 kilometres to attend the closest health facility.

The simulated patient transcripts indicated that 5 of 6 intervention clinicians and 5 of 10 comparison clinicians engaged with adolescents in a fairly responsive and nonjudgmental way, and also provided them with adequate, basic information. The 
remaining 5 comparison clinicians and 1 intervention clinician were instead moderately to extremely judgmental in their comments, and provided little or none of the appropriate information. In one example from a comparison health facility, a girl requested birth control from a health worker who responded abruptly and rudely, interrogating her about her parents' names and village, and stating that the girl was "most primitive" and "never went to school" when she did not take her shoes off prior to getting on the examination table. The health worker ultimately asked her if she wanted injectable or oral contraceptives, without explaining them to her. She requested oral contraceptives, which the health worker gave her after a brief physical examination. However, the health worker's criticism continued: "Who taught you about it? That you should go for family planning pills?... A young person like you, why do you hate having babies? Hmm, we provide [contraceptives], yes, that's fine. But you haven't - haven't even had a baby. [It would be acceptable] if a baby is disturbing you, or your husband doesn't care about you. But a young person like you, you have just begun hating to have babies" [SPE-00-C-24-10f].

Villagers and health workers consistently reported that the only women who used modern contraceptives were a limited number of single or married mothers, who mainly used Depo Provera, or, to a lesser extent, oral contraceptives. Depo Provera injections were popular because of their infrequent administration, and less chance of detection by sexual partners and others. For example, a 22 year old single mother who had children by different fathers reported that she used Depo Provera injections, but she hid this from her mother because she would disapprove of her continued sexual activity. In another example, one of the PO reported that: "[A male health officer] told me about a woman who, after [secretly] using the [Depo Provera] injection method, did not get pregnant. Her husband took her to a traditional healer to get medicine to help her get pregnant. [She] was given a traditional medicine, but didn't take it. Instead, she emptied it slowly over time, pouring out the amount she had been told to drink every day" [PO-01-C-3-3m].

Very few young women reported use of oral contraceptives, and those who did tended to have more formal education than most villagers. For example, during a PO interview, a village health officer reported that his wife used oral contraceptives, and showed the researcher her pills. Many respondents voiced wariness of hormonal methods, and particularly oral contraceptives, because they were widely reported to have negative side effects, such as weight loss or increase, continuous or sporadic menstrual bleeding, reproductive cancer, and infertility. For example, a mother of nine who was relying on a traditional contraceptive at the time of the research said that: "The traditional healer gave her [the traditional contraceptive] wrapped in a little piece of a cloth, and instructed her to put it on top of the wall inside her house until she wants to conceive, when she should take it down again by herself. ... Before using the traditional contraceptives, she used injections [Depo Proveral for a year. She said that few women use such methods because they believe the medicines are dangerous and cause cancer ... and some are said to have a rotting uterus after using contraceptive pills or injections for a long time" [PO-01-C-2-5f].

One of the most commonly cited concerns about both traditional and modern contraception, and especially oral contraceptives, was that they could harm a woman's long-term fertility as described by one PO informant: "She told me that parents would prefer their daughter to get pregnant before getting married rather than use contraceptives that will completely damage their reproductive system. She gave me an example of a Standard 7 girl whose younger sister showed their mother her contraceptives. That mother became very angry, and beat 
the girl very severely, as she thought she was intending to destroy her reproductive system" [PO02-I-4-5f].

While such beliefs were mainly reported in informal village discussions, the simulated patient exercises suggest that information patients received in health facilities might have sometimes also perpetuated misunderstandings about modern contraceptives. In the following exchange in an intervention health facility, an adolescent requested a birth control method, and the clinician responded by encouraging her to use condoms. In the process, the clinician suggested that both oral and injectable contraceptives were poor alternatives to condoms, because they might damage the girl's short-term or long-term fertility.

Most PO and GD participants had heard of male condoms, but condoms were generally associated with prevention of sexually transmitted infections rather than contraception. Very few respondents reported personal experience of them, or believed that others in their village used them. Most people reported negative beliefs about condoms particularly that they reduce male sexual pleasure, which was critical to the decision to use condoms, as males generally determined whether condoms were used within a sexual relationship. Some male respondents, for example, referred to condom use as eating ugali (a porridge staple) made from corn rather than cassava, because ugali made from cassava was considered more smooth and delicious, like intercourse without a barrier. However, there were many other widely reported negative beliefs about condoms, e.g. that they indicate distrust in a partner, contain HIV even when new, were immoral or culturally alien, might break, and/or were difficult to access. As a result, even when condoms were free, few people reported using them. The following account was provided by a pregnant 25 year old mother of two, who was separated from her husband at the time of the interview: "She said that condoms are given away free to expectant women at the dispensary, even without a woman asking for them. She said that they are advised to use condoms for family planning and to prevent STIs.... She said she has a pile [of condoms] at home, and has no plan of using them" [PO-00-C-3-2f].

Rarely, school girls reported having used condoms for one or two sexual encounters after learning about them in their MkV school lessons, and/or due to unusually great fear of pregnancy, such as a girl who did not want to lose a hard-won place in secondary school. Condoms could be purchased at village shops or obtained free from health facilities, but it could be very awkward for adolescents to access them even in the best of circumstances, as illustrated by a male simulated patient's experience requesting condoms in a comparison health facility. He was told by a health worker: "A young boy like you, you put on a condom! Who has sent you here for them? A youth like you! Whose son are you?

... My God! A young boy like that, you want to do those things, young like that? ... Now, just stay here and let me find some for you. ... You should not get accustomed to these things; you're still a young person. My God! The day it bursts, you might even acquire diseases. You're still so young. Do you hear me? ... [Later] If you are so desperately in need of having sexual intercourse, as a natural desire of the human body, it is better that you use them than not, isn't it so? " [SPE00-C-20-9m].

Occasionally, individuals mentioned other possible contraceptive methods, such as Norplant, the female condom, vaginal microbicides, withdrawal, the calendar method, and sterilisation, but it was rare for any to report personal experience of them. 


\section{Beliefs about fertility protection and promotion}

As already discussed, having children was a highly valued life goal in rural Mwanza Region. As a result, protection and promotion of future fertility was paramount even when young, unmarried women did not immediately want to become pregnant. Thus, if girls believed that a contraceptive might affect their long-term fertility, they would generally rather risk immediate pregnancy than later infertility. For example, the following account was provided by a Standard 7 girl who was the daughter of a Pentecostal preacher: "She said that pregnancy before marriage was unwelcome in most families. She said that if she happened to get pregnant, she ... would be sent away from home to go and live with the man responsible. ... She mentioned that [a certain girl] told her to give her money to prepare a traditional contraceptive for her ... a powdery concoction to mix with water and drink before sex.... [But] the informant refused to use traditional contraceptives, because she fears being infertile in the future. She said that people say traditional contraceptives are only good for people who have given birth, not girls [who have never been pregnant]" [PO-01-I-1-2f]. When the researcher returned to that village one year later, this young woman was pregnant and had been thrown out of her father's house, and was rumoured to be living with her maternal grandmother in Mwanza City.

Once married, a woman's priority usually quickly shifted to becoming pregnant. If she experienced infertility or miscarriage, these could be attributed to physical causes (e.g. STIs, contraception, or abortion history for females; "cold" sperm or one testicle for males) and/or supernatural causes (e.g. God's will, witchcraft or ancestral punishment). For example, a 17 year old woman who had recently completed Year 7: "She said she doesn't use any contraceptives because she knows she can't get pregnant. She said she has michango which cause her a lot of pain during her monthly period. ... She was told that the moment she takes traditional medicine to cure the problem, she will conceive" [PO-00-C-3-2f].

Mchango (pl. michango) is a Swahili word that officially means "intestinal worm", but in rural Mwanza was often used interchangeably with the Sukuma term nzoka (literally "snake"), to mean a broad range of symptoms and illnesses which might have supernatural causes and can only be treated effectively with traditional medicine. An infertility-related mchango/nzoka was often characterised by severe menstrual cramping and bleeding, e.g. nzoka ya buhale. Some participants perceived mchango/nzoka to actually have a snake-like form. For example: "The informant said that the michango could pierce a woman's womb and cause her to have a miscarriage.... He gave the example of [a certain woman], who ... had several miscarriages and had to take traditional medicines, [after which] she had her current child" [PO-01-C-2-1m].

There was very little opportunity for biomedical treatment of infertility in rural Mwanza, so treatment attempts were almost entirely traditional in nature. Traditional medicines used to treat infertility caused by an STI or mchango usually consisted of specific plant roots that were prepared for the woman to ingest, although there were also reports of medicines being placed in a woman's vagina (kwipagila), marked on her body, or left at a crossroads to be stepped on so that the condition is taken away by another woman. An example provided by a 27 years old man: "He told me that [his girlfriend's] condition had become worse and that she had been taken to the hospital. She had been taking some local plants [to become pregnant] which she was given by a certain man who ... had been taught about it by his late grandmother. He said that the traditional medicine had affected her, because she had been given a large dose and hence it had burnt her abdomen" [PO-99-C-2-1m]. 
Once a woman became pregnant, most beliefs about carrying a healthy pregnancy to term related to adequate nutrition and rest, and not over-exerting herself. One PO researcher observed in his field notes that this seemed more difficult to achieve for young women who were pregnant out-of-wedlock: "Those women who get pregnant within marriage receive early services; sometimes their husbands even take them to the health facility and do [extra] domestic chores. In the household where I am staying, [an unmarried girl] is pregnant. I see that there isn't any relief for her, relief that is normally given to those who are pregnant when doing different domestic work. ... I feel this situation is causing her to be weak, which she shows most of the time" [PO-01-I-1-3m].

Across the study districts, problematic pregnancies were frequently explained in terms of supernatural forces, but the interpretation often differed depending on whether it was first-person or third-person accounts. When women explained their own problematic pregnancies in terms of supernatural forces they usually attributed them to other people's maliciousness and witchcraft. For example, a 42 year old widow with eight children described the negative outcome of her sixth pregnancy: "IIn her ninth month of pregnancyl, one day she felt something protruding from her private parts ... she found someone with a bicycle to take her to the hospital. ... She said that she [miscarried] because of the mischief [witchcraft] of people of that village. ... She said people who don't have children are not happy when they see other women deliver without problems" [PO-00-I-4-4f].

In contrast, when respondents explained other women's problematic pregnancies and deliveries in supernatural terms, the problems were sometimes explained as punishment for her immoral behaviour. For example, many respondents reported that, if a pregnant woman had sex with a man other than the one who impregnated her, she would encounter certain dangers during delivery (lwikelo). In fact, difficult deliveries were sometimes taken as evidence of a woman's infidelity in pregnancy. This belief was reported in all four districts, with many accounts involving mothers- and fathers-in-law discovering a daughter-in-law's infidelity. No respondents reported that they had experienced lwikelo themselves.

Lwikelo was related to a belief that, after conception, a sexual partner's sperm or blood influenced foetal development. While fluids from the child's father were believed to help the foetus grow, fluids from another man were believed to confuse it, and make it move upwards towards her chest, possibly harming the mother and child. In two districts, the foetus was specifically reported to try to emerge from her mouth during delivery. For example: "He said that if a woman becomes pregnant and continues to have sex with different men, then ... the child would want to burst through his/her mother's liver and ribs and might come out of the mouth" [PO-02-I-4-1m].

It was reportedly that Lwikelo could be treated during delivery if the woman swallowed traditional medicines and named her lovers. For example: "[The informant reported] if the woman takes traditional medicines, she will vomit, and she will have to mention the names of any sex partners she has had other than the man who caused the pregnancy. ... He said that [a certain man's] daughter-in-law was in the hospital when she had that problem, but she was given those [traditional] medicines and then delivered her child safely" [PO-01-C-2-6f].

\section{Discussion}

Little research has examined contraceptive and fertility beliefs and practices in Sub- 
Saharan Africa at different stages of rural young women's lives, particularly for school pupils (Williamson et al., 2009). Our study found that many rural school girls were sexually active and highly motivated to prevent pregnancy, but relied on traditional methods that were similar to those documented by Tanner (1955) in his ethnographic research with the Sukuma in the mid-twentieth century. He observed: "Every girl wears a string of coloured beads of one or more strands round her thighs, from the time of puberty ... To these strings are added various protective medicines of a female nature such as to prevent conception during casual love affairs or to ensure the fertility of the wearer during her marriage".

Young, single mothers in our study had better access to modern contraceptives than adolescents who had not borne children, but many chose not to use them. This may reflect external pressures related to their fertility, ambivalent personal desires, and a general openness to chance, as has been found elsewhere in Sub-Saharan Africa (Johnson-Hanks, 2005). It may also result from contradictory information they received about possible side effects from family planning providers and informal village discussions.

Given the desire for effective contraception amongst many young women, there is a critical need both to improve access to and to correct misinformation about modern contraceptives in rural areas. Concerns about potential side effects of modern contraceptives, particularly oral contraceptives and condoms, were very similar to those documented in other studies in Tanzania (Mgalla \& Boerma, 2001; Allen, 2002) and elsewhere in Sub-Saharan Africa (Rutenberg \& Watkins, 1997; Castle, 2003; Westhoff, 2003; Wood \& Jewkes, 2006; Williamson et al., 2009). Many of the reported side effects of hormonal contraceptives are known possibilities in the short-term (e.g. menstrual or weight change) and the long-term (e.g. delayed return to fertility once an injectable contraceptive is discontinued) (Castle, 2003; Westhoff, 2003). However, some widely reported side effects had no scientific basis, such as permanent infertility. It may be that information about possible negative health effects provided during family planning counselling sessions (e.g. possible associations of hormonal contraceptives with specific cancers), may be misstated by clinicians, and/or misunderstood or exaggerated by patients afterwards. As Mgalla and Boerma (2001) found in their study of infertility in another rural Mwanza district, the limited health education available in school or health facility settings may sometimes be integrated with existing incorrect beliefs, reinforcing them by making them appear more scientific and credible.

Young women were also sometimes concerned about the impact that both traditional and modern contraceptives might have on their long-term ability to reproduce, underlining the fundamental importance of future fertility, and their potential anxiety related to it. As Castle (2003) found in her study of young people in Mali, unmarried women's contraceptive decision-making was often not driven by a current need to limit fertility (or current issues like accessibility, availability, and cost of methods), but rather by a future need to maximise it, in order to raise status through childbearing in their marital households. Similarly, in her ethnographic research on maternal health in a Sukuma village in the neighbouring Shinyanga Region of Tanzania, Allen (2002) found that many women were concerned from an early age about both physical and spiritual factors that may affect their ability to conceive or give birth in the future. 
Young single women's active concern to protect and promote their future fertility may represent an opportunity for condom social marketing campaigns. Unlike hormonal contraceptives, condoms were not rumoured to affect long-term fertility. Importantly, to the contrary, since condom use reduces the chance of STI transmission, condom use could specifically be promoted as a means to protect future fertility. While these findings suggest a promising approach to condom promotion with young women in Sub-Saharan Africa, it is important to recognise that other barriers to condom use remain high (e.g. the male decision-making role, multiple misconceptions, and the reduction in sensation) (Plummer et al., 2006), and these must also be addressed for any condom intervention to be effective.

This study primarily focused upon young women who were not married, and/or who had not yet begun child-bearing. However, the nature of participant observation meant that researchers also often interacted with young married individuals and collected data from them as well. Our findings that newly married women rarely attempted traditional or modern contraception were in keeping with traditional beliefs that adults were not "whole" or "complete" (mhola) until they had had children (Brandström, 1990), and that they must prove their fecundity with a first child before consideration of birth control for child spacing purposes (Varkevisser, 1973).

STI syndromic management and basic prenatal and delivery care in rural health facilities probably ensured that some potentially adverse birth outcomes were avoided during the study period. However, the dearth of clinical infertility services, combined with widespread traditional beliefs about health and illness, meant that women who were concerned about infertility almost exclusively pursued traditional treatments for it. For example, many of the symptoms which were believed to indicate an infertility-related mchango (e.g. nzoka ya buhale) may have related to conditions like endometriosis, but their biomedical diagnosis and treatment was rarely possible, and traditional treatments were often pursued instead. Our study found that some of those traditional treatments such as those for perceived infertility, or for certain kinds of difficult labour - may be at best ineffective and at worst emotionally and physically harmful.

Notably, our findings that certain problematic deliveries were attributed to a woman's promiscuity (lwikelo) are similar to those of studies conducted elsewhere in Mwanza Region and in neighbouring Shinyanga Region. More than thirty years ago, Varkevisser (1973) also described beliefs about lwikilo (sic) as a condition in which a child tried to emerge from a mother's mouth, for which the mother must divulge her sexual partners' names and receive treatment from a traditional healer. More recently, in neighbouring Shinyanga Region, Allen (2002) witnessed a prolonged, stalled labour at which the birth attendant, a traditional healer who specialized in pregnancy and delivery care, treated the woman with herbal medicine for usangalija, a condition in which the child moves towards the woman's chest as a result of her promiscuity during pregnancy. After 24 hours, the woman was moved to a hospital, where hospital staff noted that her full bladder had probably impeded her child's descent. Her child died soon after delivery.

A unique strength of this qualitative study is that it was conducted over a large geographic area, involving participant observation in nine villages, group discussions and in-depth interviews in three others, and simulated patient exercises in 16 health facilities, which together may have maximized data validity and representativeness of 
the data for rural Mwanza Region. In addition, the focus on adolescent girls and young, unmarried women addresses a gap in the literature on contraceptive and fertility beliefs and practices amongst rural women. However, a possible limitation of this study is that, as in any qualitative research, unusual and problematic accounts may have received a disproportionate amount of attention in formal and informal interviews, while relatively mundane and uneventful beliefs and experiences were underrepresented. Beliefs about lwikelo, for example, while clearly widespread in the region, are unlikely to frequently play a role in young women's pregnancies or deliveries. In addition, in this study, the limited nature of data collected on women in their older reproductive years meant that their contraceptive beliefs and practices could not be addressed in depth here.

There is a critical need for improved reproductive health education and services in rural areas, including interventions to address widespread misconceptions about hormonal contraceptives and condoms, increased access to modern contraception for sexually active young people who have not borne children, and improved fertility services for women who have difficulty conceiving and prenatal care for pregnant and delivering young women. Condom promotion campaigns may be more successful if they emphasise both the contraceptive value of condoms, and that condoms may protect future fertility through STI prevention.

\section{Acknowledgements}

We benefited greatly from the dedicated work of Halima Abdallah and Neema Busali for their part in data collection, Bernadette Cleophas-Frisch for helping to coordinate and conduct the simulated patients study, Caroline Ingall for initial summarising of some of the data, and Richard Hayes for his valuable comments on an earlier version of the manuscript. We are also very grateful to study transcribers, translators, data coders, and the MkV trial intervention and impact evaluation staff. We thank the Tanzanian Medical Research Coordinating Committee for permission to carry out and publish the results of this study. The study was funded by the Medical Research Council (MRC), UK. Drafting of the article was supported by additional funds from the MRC Social and Public Health Sciences Unit, Glasgow, UK, and a British Academy Post-doctoral Fellowship (MP).

Received 8 February 2010

Revised 29 April 2010

Accepted 2 May 2010

\section{References}

Allen, D.R. (2002) Managing Motherhood, Managing Risk: Fertility and Danger in West Central Tanzania. Ann Arbor: University of Michigan Press.

Brandström, P. (1999) Seeds and soil: The quest for life and the domestication of fertility in Sukuma-Nyamwezi thought and reality. In A. Jacobson-Widding and W. van Beek, eds. The Creative Communion: African Folk Models of Fertility and the Regeneration of Life. Stockholm, Sweden: Almqvist and Wiksell International. Pp. 167-186. 
Caldwell, J.C. \& Caldwell, P. (1987) The cultural context of high fertility in sub-Saharan Africa. Population and Development Review 13, 409-437.

Castle, S. (2003) Factors influencing young Malians' reluctance to use hormonal contraceptives. Studies in Family Planning 34, 186-199.

Chen, S. \& David, K.G. (2003) Determinants of contraceptive method choice in rural Tanzania between 1991 and 1999. Studies in Family Planning 34, 263-276.

Cohen, B. (1998) The emerging fertility transition in sub-Saharan Africa. World Development Review 26, 1431-1461.

Dyer, S.J. (2008a) Infertility-related reproductive health knowledge and help-seeking behaviour in African countries. ESHRE Monographs 1, 29-33.

Dyer, S.J. (2008b) Infertility in African countries: Challenges created by the HIV epidemic. ESHRE Monographs 1, 48-53.

Harwood-Lejeune, A. (2000) Rising age at marriage and fertility in southern and eastern Africa. European Journal of Population 17, 261-280.

Hayes, R.J., Changalucha, J., Ross, D.A., Gavyole, A., Todd, J., Obasi, A.I.N., Plummer, M.L., Wight, D., Mabey, D.C. \& Grosskurth, H. (2005) The MEMA kwa Vijana Project: Design of a community-randomised trial of an innovative adolescent sexual health intervention in rural Tanzania. Contemporary Clinical Trials 26, 430442.

Hinde, A. \& Mturi, A.J. (2000) Recent trends in Tanzanian fertility. Population Studies $54,177-191$.

Johnson-Hanks, J. (2005) When the future decides: Uncertainty and intentional action in contemporary Cameroon. Current Anthropology 46, 363-385.

Kirk, D. \& Pillet, B. (1998) Fertility levels, trends, and differentials in sub-Saharan Africa in the 1980s and 1990s. Studies in Family Planning 29, 1-22.

Larsen, U. (2000) Primary and secondary fertility in sub-Saharan Africa. International Journal of Epidemiology 29, 285-291.

Larsen, U. (2003). Primary and secondary infertility in Tanzania. Journal of Health and Population in Developing Countries 5, 1-15.

Mgalla, Z. \& Boerma, J.T. (2001) The discourse of infertility in Tanzania. In J.T. Boerma \& Z. Mgalla, eds. Women and Infertility in Sub-Saharan Africa: A Multi-disciplinary Perspective. Amsterdam, Netherlands: Royal Tropical Institute, KIT Publishers. Pp. 189-200.

National Bureau of Statistics and ORC Macro (2005) Tanzania Demographic and Health Survey 2004-05. Dar es Salaam, Tanzania: National Bureau of Statistics and ORC Macro.

Obasi, A.I., Cleophas, B., Ross, D.A., Chima, K.L., Mmassy, G., Gavyole, A., Plummer, M.L., Makokha, M., Mujaya, B., Todd, J., Wight, D., Grosskurth, H., Mabey, D.C. \& Hayes, R.J. (2006) Rationale and design of the MEMA kwa Vijana adolescent sexual and reproductive health intervention in Mwanza Region, Tanzania. AIDS Care 18, 311-322.

Plummer, M.L., Wight, D., Wamoyi, J., Mshana, G., Hayes, R.J. \& Ross, D.A. (2006) Farming with your hoe in a sack: Condom attitudes, access, and use in rural Tanzania. Studies in Family Planning 37, 29-40.

Plummer, M.L., Wight, D., Wamoyi, J., Nyalali, K., Ingall, T., Mshana, G., Shigongo, Z.S., Obasi, A.I.N. \& Ross, D.A. (2007) Are schools a good setting for adolescent 
sexual health promotion in rural Africa? A qualitative assessment from Tanzania. Health Education Research 22, 483-499.

Plummer, M.L., Wamoyi, J., Nyalali, K., Mshana, G., Shigongo, Z.S., Ross, D.A. \& Wight, D. (2008) Aborting and suspending pregnancy in rural Tanzania: An ethnography of young people's beliefs and practices. Studies in Family Planning 39, 281-292.

Ross, D.A., Changalucha, J., Obasi, A.I.N., Todd, J., Plummer, M.L., Cleophas-Mazige, B., Anemona, A., Everett, D., Weiss, H.A., Mabey, D.C., Grosskurth, H. \& Hayes, R.J. (2007) Biological and behavioural impact of an adolescent sexual health intervention in Tanzania: A community-randomized trial. AIDS 21, 1943-1955.

Rutenberg, N. \& Watkins, S.C. (1997) The buzz outside of clinics: Conversations and contraception in Nyanza Province, Kenya. Studies in Family Planning 28, 290-307.

Silberschmidt, M. \& Rasch, V. (2001) Adolescent girls, illegal abortions and "sugar daddies" in Dar es Salaam: Vulnerable victims and active social agents. Social Science and Medicine 52, 1815-1826.

Tanner, R.E.S. (1955) The sexual mores of the Basukuma, Tanganyika. The International Journal of Sexology, 8(4), 238-241.

Terceira, N., Gregson, S., Zaba, B. \& Mason, P.R. (2003) The contribution of HIV to fertility decline in rural Zimbabwe, 1985-2000. Population Studies 57(2), 149-164.

Varkevisser, C.M. (1973) Socialization in a Changing Society: Sukuma Childhood in Rural and Urban Mwanza, Tanzania. The Hague: Center for the Study of Education in Changing Societies (CESO).

Westhoff, C. (2003) Depot-medroxyprogesterone acetate injection (Depo-Provera): A highly effective contraceptive option with proven long-term safety. Contraception 68, 75-87.

Wight, D., Plummer, M.L., Mshana, G., Wamoyi, J., Shigongo, Z.S. \& Ross, D.A. (2006) Contradictory sexual norms and expectations for young people in rural northern Tanzania. Social Science and Medicine 62, 987-997.

Williamson, L.M., Parkes, A., Wight, D., Pettigrew, M. \& Hart, G.J. (2009) Limits to modern contraceptive use among women in developing countries: A systematic review of qualitative research.

Wood, K. \& Jewkes, R. (2006) Blood blockages and scolding nurses: Barriers to adolescent contraceptive use in South Africa. Reproductive Health Matters 14(27), 109-118. 